A RT I G O

$\infty$

\title{
A luta pelo Direito À Saúde no Brasil
}

\author{
José Gomes Temporão ${ }^{a}$
}

a Pesquisador do Centro de Estudos

Estratégicos-FIOCRUZ, Doutor em Medicina

Social, Membro Titular da Academia Nacional

de Medicina, Ex-ministro da Saúde.

E-mail: jose.temporao@fiocruz.br

\section{Resumo}

$\mathrm{O}$ artigo recupera as origens do Movimento da Reforma Sanitária Brasileira (MRSB) e de construçáo do Sistema Único de Saúde (SUS) e analisa seu desenvolvimento ao longo das últimas décadas, suas conquistas, os obstáculos enfrentados e os desafios que se colocam para o futuro.

\section{Palavras chave}

Saúde pública, saúde coletiva, sistema único de saúde, políticas de saúde, reforma sanitária

\section{Abstract}

The article recovers the origins of the Brazilian Sanitary Reform Movement (MRSB) and the construction of the Unified Health System (SUS) and analyzes its development over the past decades, its achievements, the obstacles faced and the challenges that are posed for the future.

\section{Keywords}

Public health, collective health, unified health system, health policies, health reform

\section{Das Caixas de Aposentadorias e Pensóes ao SUS}

A luta pelo direito à saúde no Brasil se caracteriza por um complexo processo que, em cada conjuntura é influenciado por um conjunto de fatores setoriais fortemente vinculados ao contexto político e social mais amplo, o que lhe dá um rosto distinto, especifico em cada um desses momentos.

Proponho uma viagem no tempo que tem início no período que antecede a Constituição de 1988 e o movimento denominado de Reforma Sanitária Brasileira. Vamos rever o que inspirou essa jornada, um processo político e social de longa duração, cujas raízes se remetem a Oswaldo Cruz e sua luta 
contra a febre amarela, a peste bubônica e a varíola no início do século $X X$.

Já na década de 20, o Brasil aprovou uma lei que instituía caixas de aposentadorias e pensóes (CAPS) por categoria de trabalhadores, onde as entidades representativas de trabalhadores organizavam suas próprias estruturas de proteçáo social. Nesse contexto, entre as principais demandas, encontra-se a atenção à saúde. Essa legislação (Lei Elói Chaves) foi aprovada em uma conjuntura onde eclodiu um forte movimento operário anarquista e socialista por melhores condições de trabalho, salário, contra o trabalho infantil e em defesa do direito de greve e de livre organização. Naquela época crianças trabalhavam dez horas por dia em fábricas insalubres, em condiçôes dramáticas. A maior parte dessas lideranças foi perseguida, presa e deportada, muitos eram imigrantes italianos ou de outras origens. Mas esse foi o primeiro passo concreto para um sistema de proteção e atenção aos trabalhadores e suas famílias.

Já no Estado Novo de Getúlio Vargas, essas caixas de aposentadorias se transformaram em institutos de aposentadorias e pensôes (IAPS). E aí surge uma inovação, na medida em que os IAPS eram financiados e gerenciados pela Uniáo, sindicatos patronais e sindicatos de trabalhadores. Essa estrutura se mantém até 1965 quando, já na ditadura militar, os institutos são unificados num único Instituto Nacional de Previdência
Social (INPS). Situação que vige até hoje. E em 1977, as funções de assistência médica do INPS foram transferidas ao Instituto Nacional de Assistência Médica da Previdência Social (INAMPS) especificamente voltado para assistência médica, o antigo INAMPS, que foi extinto quando o SUS foi criado ${ }^{1}$.

As principais características desse modelo que vige até o surgimento do SUS, são ${ }^{1}$ : 1 - A separação entre as açóes de saúde pública (campanhas de caráter nacional por patologia, grandes endemias, saúde materno-infantil) e a assistência médico-hospitalar.

2 - O componente de assistência médica, cresce principalmente, através da compra de serviços privados, predominando a prática médica individual e especializada.

3 - Privilegiou os trabalhadores urbanos com vínculo formal de trabalho.

$\mathrm{Na}$ prática, os extratos mais ricos eram atendidos por serviços particulares; os trabalhadores e familiares no início por sistemas de caixas beneficentes e associaçóes de mútuo socorro, e depois pelo sistema previdenciário; mas a maioria da população, dependia da caridade, da filantropia e dos incipientes serviços de atenção municipal ou das campanhas do governo federal por patologia (tuberculose, malária, saúde mental, saúde materno infantil etc.). 
Isso se mantém até o advento do SUS.

Esse modelo, portanto, não era universal e organizava a estrutura de oferta por categorias profissionais representadas por seus sindicatos ou associaçóes. Os setores econômicos com mais poder e recursos financeiros, podiam estabelecer uma oferta de maior qualidade para seus associados. Então, era um modelo onde havia muita desigualdade.

Foram as contradiçôes criadas e acumuladas por esse modelo e agravadas pelos resultados da política econômica no campo social durante os anos 70 e 80 do século passado, que estáo na raiz do surgimento do movimento da reforma sanitária brasileira-MRSB- que passa a defender uma radical reforma do sistema de saúde brasileiro a partir de uma visão médico-social.

O MRSB se estrutura no contexto da luta pela reconquista da democracia, onde o direito à saúde ganha uma nova dimensão e conforma um movimento englobando a academia, igrejas, sindicatos, movimentos sociais, partidos políticos, entidades da área da saúde, profissionais de saúde entre outros atores relevantes. Isso foi fundamental para as mudanças que estavam por vir. Todos unidos em torno de um conjunto de ideias sobre as relaçóes entre saúde e democracia, e sobre a importância de reformas estruturais na sociedade brasileira que pudessem reverter o grave quadro de injustiça social e desigualdade acelerado durante o regime militar ${ }^{2}$. Ou seja, o movimento continha uma crítica ao que foi construído até ali e uma proposta de radical reforma da saúde brasileira, a partir de uma visão médica, mas também social. Então, a luta pela democracia na ditadura foi um momento de inflexão, de ruptura para a saúde brasileira ${ }^{3}$.

Um dos atores políticos mais importantes do período foi o Centro Brasileiro de Estudos da Saúde (CEBES), criado em 1976, por David Capistrano Filho, Sérgio Arouca e José Rubem de Alcântara Bonfim em São Paulo. Inicialmente com o objetivo de publicar a Revista Saúde em Debate que se transforma no espaço de divulgação de artigos e teses que dão suporte ao novo conjunto de ideias e propostas de reforma da saúde brasileira. O CEBES surge, então, como movimento político que se nutriu do passado, mas a partir de uma reflexão política dessas experiências, uma reflexão teórico-conceitual começa a construir uma nova agenda, um novo olhar sobre a saúde brasileira contemporânea.

Todo esse movimento, compôs um ideário claro e objetivo que se expressa na VIII Conferência Nacional de Saúde, realizada em 1986, que foi a primeira a contar com ampla participação da sociedade. O Brasil tem uma grande tradição em Conferências de Saúde, mas até a $7^{\text {a }}$ Conferência, realizada em 1980, só participavam delas, especialistas, convidados e governo.

$\mathrm{O}$ que nos inspirou como referências históricas e conceituais nesse processo onde 
predominam os conceitos de humanismo, democracia, justiça social, desenvolvimento humano e científico? Uma forte inspiração veio principalmente do sistema de saúde inglês, canadense e de outros sistemas universais, como a experiência de Cuba, mas também o movimento de Alma-Ata, que passa a inspirar várias iniciativas de prefeituras, como as de Niterói, Campinas, Londrina, o projeto Montes Claros, assim como o projeto federal do Programa de Interiorização de Açôes de Saúde e Saneamento (PIASS); experiências essas, voltadas para a construção de um sistema de saúde com recorte universal centrado na atenção primária e fortemente baseada na integração com as demais políticas sociais.

Mas na verdade, os médicos reformistas europeus do século XIX já trabalhavam com essa consciência do social na saúde e já afirmavam, que seria obrigação da sociedade assegurar e proteger a saúde dos seus membros, sendo que as condiçôes sociais e econômicas teriam uma importância fundamental na saúde da população. Ou seja, já afirmavam que a saúde é socialmente e politicamente determinada.

Virchow já dizia que "a medicina é uma ciência social e a política nada mais é do que a medicina em grande escala" ${ }^{4}$.

E o que o relatório da VIII CNS trazia de inovador?5

- o conceito de Saúde, relacionado com todos os seus determinantes, como tra- balho, salário, alimentação, habitação, transporte, cultura, meio ambiente, entre outros; incorpora o conceito de Determinação Social da Saúde que aponta para a necessidade de mudanças estruturais na sociedade que impactem as condiçôes de vida, reduzam as desigualdades e as iniquidades que se expressam nos indicadores de saúde ${ }^{6}$.

- defende o direito universal e igualitário à Saúde; ou seja, a saúde deixava de ser um direito vinculado ao trabalho ou relacionado ao poder de compra, e passava a ser um direito de cidadania

- reitera o dever do Estado na promoção, proteção e recuperação da Saúde;

- enfatiza a natureza pública das açóes e serviços de Saúde;

- propóe a organização das açôes em uma rede regionalizada e hierarquizada, constituindo um Sistema Único de Saúde gratuito, descentralizado para Estados e municípios

- Defende a democratizaçáo através da implantação de um modelo de controle social constituído pelas Conferências de Saúde e pelos Conselhos de Saúde.

Ou seja, o conteúdo da proposta original do SUS, foi de compreender a Saúde como um direito, sendo que em seu componente assistencial, organizado através de um sistema unificado, descentralizado, democrático e universal; que defendia a integrali- 
dade da atenção, combatia a privatização do sistema através da redução gradual da oferta privada e ampliação da oferta pública de serviços de saúde; e defendia o fortalecimento da capacidade nacional da produção de insumos estratégicos para a Saúde 5 .

É esse conjunto de princípios que vai orientar os debates sobre saúde na Assembleia Nacional Constituinte.

Mas enquanto o debate se estabelecia no congresso nacional, é preciso destacar a conjuntura que vai de 1985 a 1988. Assume o ministério da Previdência Social, Waldir Pires que nomeia Hésio Cordeiro como presidente do INAMPS. Já o novo ministro da saúde é o baiano Carlos Santana que nomeia Sérgio Arouca para presidir a Fundação Oswaldo Cruz. Tanto no Inamps quanto no MS são constituídas equipes compostas por jovens sanitaristas defensores da proposta da saúde universal e democrática. Nesse contexto o polo mais dinâmico do processo de unificação e descentralização do sistema de saúde se organiza no INAMPS detentor do maior orçamento no campo da saúde e com grande peso político e assistencial. O INAMPS estabelece uma nova política, as Ações Integradas de Saúde (AIS) como estratégia de reorientação setorial. As AIS se estruturam a partir de convênios com estados e municípios, fazendo a transferência pioneira de recursos financeiros da previdência social para a saúde universal, através da criação de estruturas de pactuação e construção de consenso e de integração de redes, que antecede as atuais estruturas dos conselhos de saúde e comissóes bipartites, além de estabelecer mecanismos de planejamento integrado entre MPAS e MS. Foi um período de grandes inovaçôes.

Dessa forma, de um lado, tivemos avanços no campo do pensamento e da formulação, e por outro lado, avanços no campo da mobilização e da organização de serviços, do ponto de vista prático de experiências concretas no território. Eram vários grupos e movimentos trabalhando nesse sentido, inovando, pensando diferente.

Finda a constituinte e promulgada a nova constituição, o seu artigo 196 estabelece que: "a saúde é direito de todos e dever do Estado, garantida por politicas sociais e econômicas, que visem à redução do risco de doenças $e$ de outros agravos, $e$ ao acesso universal $e$ igualitário às açóes e serviços, para sua promoção, proteção e recuperação" 7 , em uma redação, que enfatiza que a saúde, além de ser um direito de cidadania e dever do Estado, é também assegurada por políticas sociais e econômicas.

Quando analisamos as tipologias dos sistemas de saúde segundo um modelo proposto pela $\mathrm{OECD}^{8}$, temos:

1 - Modelo Beveridge: cobertura universal, financiamento proveniente dos impostos gerais e prestação pública da atenção à saúde. Nasceu no Reino Unido; hoje presente em muitos países europeus e de outros continentes. 
2 - Modelo Bismarckiano: Seguros sociais obrigatórios, cobertura universal e financiado e gerenciado por empregadores e empregados. As prestaçóes de cuidado podem ser públicas ou privadas. Alemanha é o protótipo desse tipo de sistema.

3 - Seguros privados: voluntários, financiados pelas contribuiçóes de indivíduos e empregadores, e com prestações de cuidado de saúde predominantemente privadas. Os EUA representam o paradigma desse sistema.

Além dos três modelos anteriores, temos um quarto o da medicina socializada. Instituído na União Soviética durante a Revoluçáo de 1917, e sucessivamente adotado nos países do Leste Europeu. Cuba hoje é o único país com sistema baseado na medicina socializada, sem a presença do setor privado.

Então o Brasil, dispóe hoje de um sistema construído a partir da referência do modelo Beveridgeano, com um mix de seguro privado, onde $75 \%$ da população brasileira usam, para todas as suas necessidades, exclusivamente o SUS, e $25 \%$ utilizam, para consultas, exames e internações, o setor privado, financiado principalmente pelos empregadores. Mas frise-se que, para transplantes de órgãos, medicamentos de alto custo, atenção de urgência e emergência, vacinação, vigilância sanitária e epidemiológica, todos usam o SUS.
Já, do ponto de vista histórico estrutural, temos duas grandes ideias força em constante conflito e tensão que buscam moldar o desempenho e a estrutura dos sistemas de saúde: na primeira predominaria o conhecimento biomédico e a forte relaçáo com o setor industrial e de serviços, predominando as tecnologias duras associadas sobretudo à atenção hospitalar; na segunda o que se busca é introduzir organicamente o conceito de determinaçáo social da saúde (DSS), onde a saúde é vista como processo político-social e técnico-cientifico, ou seja, aqui predominaria a intersetorialidade, a transversalidade. Esta última é muito mais complexa para ser coordenada e implementada, entretanto seria muito mais potente para atuar sobre as desigualdades em saúde.

$\mathrm{Na}$ verdade, não existe nenhum sistema de saúde no mundo que reflita de modo puro uma tendência ou outra; o que temos na prática são superposiçóes ou predomínios de um ou de outro. Por exemplo, o que mais se aproxima da primeira concepção é o sistema de saúde americano, entretanto na atualidade muitos estados dentro dos Estados Unidos têm organizado experiências inovadoras no campo da Atenção Primária e outras dimensôes que buscam uma maior aproximação com a visão da DSS. Evidente que o projeto original da Reforma Sanitária e do SUS se aproxima muito mais da segunda concepção. 
Importante destacar também que esse movimento transcendia a luta pela garantia do acesso à saúde ou da saúde como um direito. De fato, ele se via como um movimento cultural, emancipador, de transformaçáo da percepção da Saúde por uma determinada sociedade, um modelo de desenvolvimento humano, com a construçáo de um novo olhar, de novas práticas e de novos sujeitos, onde a saúde é um vetor de diálogo para outras dimensóes do campo político e social, destacando-se o conceito ampliado de saúde e a determinaçáo social da saúde. Ou seja, a ideia era transformar a sociedade através e pela Saúde. E nessa visão, o SUS seria uma das dimensões da Reforma Sanitária, mas não a única.

Em síntese, antes de 1988, tínhamos um sistema de saúde privatizado, fragmentado, descoordenado, que oferecia serviços curativos predominantemente para três tipos de brasileiros: os ricos, que pagavam pela assistência à saúde; os formalmente inseridos no mercado de trabalho, que usavam a previdência social; e a grande maioria da populaçáo brasileira que era objeto da caridade, da filantropia ou do abandono. Não é exagero afirmar que naquela época a maioria da população brasileira estava completamente desassistida e abandonada do ponto de vista de acesso e oferta de uma estrutura de qualidade, a tempo e à hora para cuidar de sua saúde. O surgimento do SUS coloca a Saúde em uma outra dimensão, em uma outra perspectiva, como direito, com um sistema descentralizado, com participação popular, e sendo dever do Estado.

Jairnilson Paim nos lembra que é importante reafirmar que nem a Reforma Sanitária Brasileira nem o SUS foram criados pelo Estado, nem por governos ou por partidos, mas nasceram do processo político na sociedade brasileira dentro desse contexto histórico?. Portanto, ele é uma conquista do povo brasileiro, uma conquista da sociedade brasileira e que, neste momento, está sob ameaça. Essa é a maior política pública que nasceu da sociedade brasileira e se estruturou na Constituição Federal como um direito de toda a população.

\section{Os OBSTÁCULOS NA CONSTRUÇÁO DO PROJETO}

Nesse caminhar enfrentou-se vários obstáculos. Analisemos alguns deles.

O Brasil é o único país que tem um sistema universal de grande magnitude e complexidade. Segundo o MS, o SUS produz praticamente quatro bilhóes de procedimentos ambulatoriais por ano, mais de um bilhão de consultas e atendimentos, 11 milhóes de internações, dois milhóes de partos, quase um bilhão de exames e aplica 300 milhóes de doses de vacinas e imunobiológicos ${ }^{10}$.

Um problema inicial, portanto, foi o próprio gigantismo e complexidade do 
projeto. Tomemos a Itália e a Inglaterra, como comparação, nesses países foram décadas de maturação entre pensar o projeto e implementá-lo, sendo que no Brasil, dois anos depois de aprovado na VIII Conferência Nacional de Saúde, o artigo 196 já estava inscrito na Constituição Federal, e dois anos depois em 1990 já tínhamos a Lei Orgânica do SUS e demos a partida dessa nova etapa de construção da saúde universal.

Um outro obstáculo a se destacar, é que desde a aprovação da lei que regulamentou o SUS, nenhum governo colocou a construção do SUS como prioridade absoluta em toda a sua radicalidade. Portanto, o SUS nunca foi uma política hegemônica ao interior dos governos. Em algumas conjunturas avançamos mais, em outras menos, mas nunca o tivemos na centralidade em torno da qual as demais dimensóes estruturais que impactam o setor saúde, estivessem organicamente vinculadas.

Um outro aspecto é que a Saúde, tem sido vista desde sempre, como gasto e não como investimento. Essa visão equivocada sobre a saúde, é disseminada pela grande mídia e por formadores de opinião de recorte liberal. Mas a esse viés pelo lado econômico, junta-se a visão de que o SUS é um importante sistema apenas para os mais pobres e que faria parte do processo de ascensão social, conquistar um plano de saúde privado.

Além disso, a saúde tem uma dinâmica econômica específica e apenas em 2000 foi criada a Agência Nacional de Saúde para regular o sistema suplementar privado, e mesmo assim capturada por interesses privados, desde o início. Entender este ponto é importante pois essa dinâmica com seus interesses e contradiçôes, fez que ao longo desses trinta anos de implementação a população coberta por planos e seguros privados tenha alcançado $25 \%$ da população. A saúde hoje é uma área que expressa grandes interesses econômicos. Então, empresas que têm ações na bolsa de valores, adquirem hospitais, e entram no sistema de saúde estabelecendo uma nova dinâmica, exigindo uma capacidade de regulação do Estado extremamente importante e desafiadora.

Aqui cabe destacar também, um aspecto central em toda essa trajetória e que está na gênese dessa contradição: o papel das centrais sindicais e dos sindicatos de trabalhadores. Se de um lado apoiaram e participaram da luta pelo SUS, na prática, quando estabeleciam seus acordos coletivos com os sindicatos patronais, colocavam como uma de suas demandas centrais, a concessão de planos de saúde para si e para suas famílias. Ou seja, desde o início, a vanguarda do operariado apoia o SUS na retórica, mas não na prática, e isso se estende aos próprios trabalhadores do SUS.

Já a questão do financiamento, tem sido um dos obstáculos mais importantes. O SUS já nasceu subfinanciado e, quando da aprovação da Lei orgânica do SUS em 1990, o 
que se esperava era que o orçamento do então INAMPS, fosse compor o orçamento do novo Ministério da Saúde. E não foi o que aconteceu. $\mathrm{O}$ que ocorreu foi que o orçamento do INAMPS foi absorvido pelo orçamento da Previdência Social, deixando que o SUS disputasse uma fatia do orçamento geral da União no conjunto da administração do Estado e das políticas públicas. Isso impactou profundamente desde o nascedouro a viabilidade do projeto e foi crucial para a manutenção até os dias de hoje da fragilidade econômico-financeira, um dos problemas estruturais do sistema.

Essa restrição de recursos constrangeu o processo de formulação de políticas, a definição de prioridades e a própria viabilidade do projeto original. Ao longo desse tempo, tivemos uma ampliaçáo do gasto privado e uma retração do gasto público. Hoje, apenas $46 \%$ do gasto total em saúde no Brasil é público ${ }^{11}$. Isso é uma contradição porque nos sistemas universais ocorre exatamente o contrário. $\mathrm{Na}$ Inglaterra, $80 \%$ do gasto total é público ${ }^{11}$. No Brasil, a maior parte do gasto em saúde é privado, seja desembolso direto das famílias com exames, consultas, medicamentos e outros procedimentos, seja gasto das empresas. Para agravar esse quadro, temos os denominados gastos tributários, que são subsídios e renúncia fiscal para pessoas físicas e jurídicas, que, segundo o IPEA retiraram do SUS cerca de 32 bilhóes de reais em 2015, para subsidiar planos e seguros de saúde do mercado privado $^{12}$. Quando comparamos os recursos investidos no SUS com a receita do setor de planos e seguros, salta aos olhos a diferença. Enquanto em 2017 o setor privado, para cobrir 47 milhóes de brasileiros dispôs, de 231 bilhôes de reais, o SUS para cobrir 150 milhôes de brasileiros em todas as suas necessidades, dispôs de apenas 201 bilhóes ${ }^{13}$. Ou seja, é absolutamente insustentável dizer que o SUS dispõe de recursos financeiros suficientes para dar conta de suas necessidades e demandas.

Esse quadro foi agravado com a aprovação da emenda constitucional 95 em 2016, que congelou os gastos em políticas sociais por 20 anos, ignorando as evidências trazidas pela transição demográfica, pelo impacto das doenças crônicas, pela pressão da incorporação tecnológica que impacta os custos da atenção. Congelar os gastos em saúde por 20 anos, comprometendo a segurança dos 150 milhóes de cidadãos que dependem totalmente do sistema público, medida aprovada por deputados e senadores que não dependem do SUS para suas necessidades cotidianas de atenção, pois usam planos e seguros de saúde, subsidiados em parte pelos impostos pagos pela sociedade; foi uma medida indecorosa.

Uma barreira menos perceptível e pouco discutida vem do choque entre os conceitos trazidos pela Reforma Sanitária, esse novo campo de pensamento, e que se expressa na Saúde Coletiva, e a hegemonia da 
medicina assistencial curativa. Podemos dizer que desde o início houve um enfrentamento entre duas visões: cuidado essencial versus medicalização. Cuidado aqui, não no sentido de intervenção técnica, mas sim um cuidado em seu sentido ontológico amplo: cuidar de um território, de uma família, cuidar das pessoas, cuidar dos cuidadores, o conceito de clínica ampliada - gestores, família e paciente, profissionais de saúde trabalhando no mesmo projeto terapêutico. Essa visão se defronta o tempo todo com a visão da necessidade de se construir hospitais, colocar mais médicos, implantar mais tecnologias duras.

Outro importante obstáculo, tem sido a oposição sistemática da grande mídia ao SUS, que agora durante o enfrentamento da Covid 19 passa a admitir a essencialidade do SUS como sistema estratégico para o desenvolvimento do país e da segurança de todos. As relaçóes da grande mídia com poderosos interesses econômicos que se expressam no campo da saúde, são bem conhecidas: indústrias de medicamentos, alimentos ultra processados, fast food, refrigerantes, pesticidas, planos e seguros de saúde entre outros.

A escassez de quadros técnicos para operar o sistema foi outro obstáculo importante. Se partimos de um sistema altamente fragmentado e centralizado e iniciamos um forte movimento de unificar o comando e ao mesmo tempo descentralizar radicalmente o sistema, era preciso dispor de quadros téc- nicos para tal operacionalização. No início desse processo, o Brasil possuía mais de cinco mil prefeituras sem nenhuma estrutura, dispondo apenas de uma visão de saúde pública tradicional, limitando-se a uma oferta tradicional em postos e centros de saúde. Esse processo demandou um enorme esforço e um grande investimento em formação de pessoal qualificado para operar essa inversão de lógica.

Um obstáculo adicional, e que persiste, foi a ausência de espaços interinstitucionais para poder construir políticas públicas de saúde integradas e articuladas a outras dimensóes econômicas e sociais. Somente em 2009 quando da aprovação do Relatório da Comissão Nacional de Determinantes Sociais de Saúde-CNDSS ${ }^{14}$, surgiram uma série de propostas como criação de instâncias de integração, no nível do governo federal, mas que nunca foram implementadas apesar de formalmente referendadas pelos presidentes da república.

\section{A CONSCIENTIZAÇÃo DA SOCIEDADE}

Um outro aspecto a ser compreendido como um obstáculo estrutural, é o que denomino de baixo grau de consciência política da sociedade brasileira sobre o valor do SUS, sobre o valor de um sistema universal.

A questão que abre esta reflexão é: como determinada sociedade vê seu sistema 
de saúde e como o valoriza: como um bem a ser adquirido no mercado? Ou, como um direito de cidadania?

Isso às vezes não é muito perceptível. As pessoas só se dão conta da importância da proteção à saúde em um momento como o que vivemos hoje, de grave ameaça à segurança da sociedade e de cada um de nós. Imaginemos se não pudéssemos contar com o SUS para enfrentar a COVID-19? Seria uma tragédia incalculável. São nesses momentos que surge com muita clareza para a sociedade, essa visão do SUS como algo a ser protegido e fortalecido.

Mas sendo o grau de consciência política em saúde de nossa sociedade baixo e fragmentado, por que isso é tão importante? A Inglaterra novamente é uma referência. Lembremo-nos da olimpíada de Londres, na cerimônia de abertura entre as conquistas que a Inglaterra mostrou para o mundo, estava lá o sistema de saúde inglês como um patrimônio da sociedade inglesa e que influenciou inúmeros outros países no desenho de seus sistemas. Isso é muito importante, porque sociedades como a inglesa ou canadense, que veem seus sistemas de saúde como um patrimônio construído por geraçôes e um bem a ser preservado, tem uma visão do seu sistema de saúde muito mais consolidada do que temos aqui entre nós. É o que está acontecendo agora durante a COVID-19. Proteção real e concreta, seja reduzindo o impacto financeiro dos gastos catastróficos, seja dando uma sensação de segurança para cada um de nós.

Mas no processo de construção da consciência política em saúde, estamos no espaço político-ideológico. Esse é um ponto absolutamente central. Como uma determinada sociedade constrói sua visão sobre a saúde? Como se constrói essa consciência, que na visão de Giovanni Berlinguer, ${ }^{15}$ é ao mesmo tempo consciência individual - como cada um percebe a "sua" saúde- mas também consciência coletiva - como a sociedade se organiza para defender esse direito, no bairro, no município, no estado, no País. Que fatores impactam a construção dessa consciência em saúde?

Esse é um processo extremamente complexo, multidimensional, com vários fatores atuando, entre outros destaco:

- Publicidades em Saúde: O impacto das publicidades em saúde difundida pelos meios de comunicação de massa. Cotidianamente a população brasileira está submetida a propagandas de remédios, hospitais, planos de saúde etc. A função desse tipo de publicidade é estimular o consumo o que acaba atuando como um vetor de fortalecimento de uma "Consciência Sanitária" distorcida ou negativa, sobre o papel hegemônico das tecnologias "duras" na manutenção e recuperação da saúde, constituindo um processo de deseducação continuada que ajuda a construir uma determinada 
visão da saúde e da assistência alienante na essência ${ }^{16}$.

- A disseminação da saúde privada como parte do processo de ascensão social e de que ela seria superior em qualidade à medicina pública, associado à visão de que o SUS é importante para atender apenas aos mais pobres (transmutação da visão da filantropia e da caridade para o SUS).

- Esse processo é impactado também, evidentemente, pelo contato da população com o sistema de atenção. Seja utilizando a Saúde da Família, internados para um procedimento em um hospital público, vítimas de um acidente, ou buscando ajuda, em sofrimento, sem acolhimento adequado, percebendo a qualidade ou não do atendimento. Esse contato cotidiano vai construindo também uma determinada visão sobre o SUS que pode ser positiva ou negativa. Ou seja, a experiência cotidiana de pacientes e usuários em suas experiências com os serviços e as políticas de saúde, são as estórias em busca de atendimento e muitas vezes um indicador negativo de iniquidades.

- E por fim o processo de medicalização, que está presente, onde a moderna medicina incorpora todos os espaços da vida social como objeto de intervenção. Marx nos ajuda a pensar esse processo de medicalização. No capitalismo, a produção não produz somente objetos para o sujeito, mas também sujeitos para o objeto ${ }^{17}$. Então, produz objetos para serem consumidos, mas também consumidores que estejam dispostos a consumir sem necessariamente necessitar.

Se o baixo grau de consciência política da população é um dos pontos críticos deste processo, o que nos permitiria medir uma ampliação dessa consciência política em saúde em nossa sociedade? Seria quando passássemos a ver o direito à saúde como um dos pilares da democracia; através de uma visão intergeracional (quando defendo a saúde universal, não defendo para mim, mas para meus filhos, netos e bisnetos, para os cidadãos do futuro); entendendo a saúde universal como um fator da redução de desigualdades e construção de equidade e, por fim, quando predomina a percepção da segurança objetiva e subjetiva que a saúde universal traz.

\section{Onde AVANÇAMOS?}

O primeiro ponto a destacar é que sim, avançamos e muito! Em 1988 tínhamos algumas experiências isoladas, muitos projetos e ideias, capacidade de mobilização e força política. Mas a base material e institucional era frágil. Hoje nós temos uma base real, temos estrutura, tecnologia, profissionais, 
pesquisadores, produção, entidades e instituições.

De todo modo, o impacto nas condiçóes objetivas e subjetivas de vida foi expressivo. Podemos afirmar que o SUS é a mais importante política de inclusão social já feita em qualquer momento de nossa história. Mas como podemos medir esse impacto positivo?

- Impacto epidemiológico: $\mathrm{Na}$ redução da mortalidade e da morbidade, no controle de doenças e agravos, de doenças imunopreveníveis. Tem sido expressivo o impacto na expectativa de vida ao nascer, na mortalidade infantil, na mortalidade por doenças crônicas, na redução da prevalência do tabagismo.

- Impacto na dimensáo Econômica: Proteção das famílias através da redução dos gastos catastróficos, criação de emprego qualificado, renda, inovação, desenvolvimento,

- Impacto na Vigilância Sanitária e Epidemiológica: $\mathrm{Na}$ qualidade e segurança de alimentos e medicamentos. $\mathrm{Na}$ segurança trazida pelo sistema de vigilância epidemiológica,

- Impacto na Estrutura e Gestáo do Estado: o SUS contém a mais importante reforma do Estado já realizada, e que está representada na descentralização, democratização e construção do arcabouço Inter federativo de pactuação e gestão de políticas.
- Impacto em outras dimensóes de políticas públicas: O SUS impacta ações e políticas em vários outros campos das políticas públicas: no serviço social, na educação, na construção da transversalidade e da intersetorialidade

- Impacto na pesquisa e na ciência brasileiras. A pesquisa em saúde representa $30 \%$ da produção científica nacional.

- Impacto no sistema de formaçáo dos profissionais de saúde, com uma grande expansão do número de profissionais formados e diversificação de profissóes.

- Impacto na organizaçáo do cuidado em saúde: construção de redes de serviços, Integralidade do cuidado e humanização,

- Impacto na reduçáo das desigualdades entre regióes e classes sociais, com a ampliação do acesso, seja dos cuidados básicos seja dos serviços de alta complexidade.

Houve uma expressiva expansão da oferta e do cuidado. Foi construída uma importante base material: hospitais, centros de saúde, policlínicas, serviços de emergência, Serviço de Atenção Móvel de Urgência (Samu), Upas, sistemas de vigilância epidemiológica e sanitária, equipamentos, equipes, tecnologias. Temos muitas experiências exitosas em planejamento e gestão, como as Normas Operacionais Básicas (NOBS) e os Pactos pela Saúde. 
Temos o maior sistema de vacinação do mundo. Nenhum país no mundo vacina dez milhôes de crianças em um único dia, como o Brasil. Em relação ao PNI ao lado dessa tecnologia organizacional, nós também desenvolvemos e consolidamos a nossa indústria de imunobiológicos. Enquanto nas décadas de 70 e 80 do século passado os países da América Latina fecharam suas empresas públicas de fabricação de vacinas e imunobiológicos, o Brasil decidiu fortalece-las instituindo o Programa Nacional de Autossuficiência em Imunobiológicos (PASNI) que através de parcerias de transferência de tecnologia com os maiores produtores mundiais ${ }^{18}$, permitiu que como resultado desse processo, Biomanguinhos e Butantã se encontrem hoje, entre os maiores produtores mundiais de vacinas e que, neste momento testam duas das mais promissoras vacinas para o corona vírus em parceria com empresas globais.

Nosso país foi o primeiro a instituir uma política universal de cuidado aos portadores de HIV e desenvolveu uma estratégia de produção de genéricos dos antirretrovirais que foi exemplo para o mundo e, em 2007 decretamos pela primeira e única vez o licenciamento compulsório de um antirretroviral (Efavirenz $^{19}$. A grande fragilidade do programa de DST/AIDS hoje está na prevenção, influenciada por setores conservadores no Congresso Nacional e parte da sociedade, que cada vez mais colocam restriçóes à discussão dos direitos sexuais e reprodutivos.
O impacto disso é o aumento da incidência de AIDS entre os jovens. Prevalecem a hipocrisia, o machismo, a intolerância e o preconceito que se expressam na violência contra gays, lésbicas e travestis. A situação é tão grave que em 2019 o MEC aprovou a retirada desse tema das bases curriculares nacionais. $\mathrm{O}$ impacto dessas medidas trará mais doença, sofrimento, mortes e estigma.

Em relação aos métodos anticoncepcionais, em 2015, 80\% das mulheres usavam métodos contraceptivos ${ }^{20}$. Já em relação ao aborto, homens conservadores querem que o direito das mulheres retroceda à década de 40 do século passado quando o código penal aprovou a interrupção de gravidez em caso de doenças graves da mãe ou gravidez decorrente de estupro. Apesar do avanço conquistado em 2012 quando o STF aprovou o direito de a mulher interromper a gravidez em caso de gestação de bebê anencefálico, a luta das mulheres nesse campo continua enfrentando imensos obstáculos.

O desenvolvimento de açóes, programas e políticas voltadas à saúde da criança se confunde com a história das políticas de saúde pública no Brasil. Entretanto, ainda não tínhamos até 2015, uma Política Nacional de Atenção Integral a Saúde da Criança (PNAISC). Seu processo de construçáo teve início em 2012 liderado pelo MS com apoio conceitual e metodológico da Estratégia Brasileirinhas e Brasileirinhos Saudáveis da Fiocruz $^{21}$. 
A Estratégia Saúde da Família que hoje cobre praticamente 150 milhóes de brasileiros, é a maior política de atenção primária do mundo e responsável por expressiva redução da morbidade e mortalidade em todo o país. A cobertura que em 2000 era de 13 milhôes (8\% pop) em 2018 alcança 154 milhôes $(74,5 \% \text { da pop })^{22}$.

Realizamos 25 mil transplantes de órgãos em 2016, sendo 90\% realizados pelo $\mathrm{SUS}^{23}$. Apenas os Estados Unidos realizam mais transplantes de órgãos do que nós; aprovamos e temos uma Política Nacional de Sangue e Hemoderivados, a Lei Sérgio Arouca. Desenvolvemos na Fiocruz e exportamos para o mundo, a tecnologia de Banco de Leite Humano.

Em relação à assistência farmacêutica aconteceram grandes avanços. A política de genéricos, além do programa Farmácia Popular e Aqui tem farmácia popular, a política de Medicamentos de alto custo para doenças crônicas, são alguns dos destaques.

O Programa Mais Médicos (PMM), se propôs a ampliar a provisão de médicos brasileiros e estrangeiros em municípios com maior vulnerabilidade, qualificar esses profissionais e investir na infraestrutura das unidades básicas de saúde (UBS). Até 2015, o PMM contava com 18.240 médicos em todo o país. O PMM tem sido palco de acalorados debates tendo de um lado, as entidades que representam os médicos que afirmavam que o Brasil já dispóe de profissionais suficientes para suprir a demanda nacional e que a grande disparidade na distribuição dos profissionais entre as regióes do país é o aspecto central do problema. Já o Ministério da Saúde estimava a necessidade de um número maior de médicos que seria inferior a muitos países da Europa e América Latina. Apesar do PMM não representar a primeira iniciativa governamental que busca atacar o problema da má distribuição de médicos; estudos preliminares apontam para o fato de que ela tem sido até o momento a mais bem-sucedida. Em 2019 o rompimento do acordo entre o MS e a OPAS que viabilizou a entrada de mais de 10 mil médicos cubanos no programa, deu início a um processo de sua substituição por médicos brasileiros.

A Política Nacional de Atenção Integral à Saúde do Homem, lançada em 2009 e desenvolvida em parceria entre gestores dos SUS, sociedades científicas, sociedade civil organizada, pesquisadores, acadêmicos e agências de cooperação internacional, foi um marco importante. Criada para promover açóes de saúde que contribuam significativamente para a compreensão da realidade singular masculina nos seus diversos contextos socioculturais e político-econômicos, a política buscou considerar a heterogeneidade das possibilidades de ser homem. As masculinidades são construídas historicamente e sócio culturalmente, sendo a significação da masculinidade um processo em permanente construção e transformação ${ }^{24}$. 
Quanto à política do tabaco, hoje, o Brasil é um dos países do mundo, com as menores taxas de prevalência de fumantes na populaçáo adulta. $\mathrm{O}$ impacto das políticas do tabaco vem sendo avaliado por várias pesquisas e a prevalência que era de mais de $30 \%$ na população adulta, agora está em torno de $10 \%$ da população adulta brasileira. A política do tabaco é exemplo importante de uma estratégia que aliou pesquisa, política pública, informação, mobilização, tratamento para os dependentes e medidas legais de restrição à propaganda, pois houve banimento da publicidade de cigarro $^{25}$.

Fizemos uma reforma psiquiátrica com fechamento dos manicômios, construção de uma rede substitutiva de cuidados (Centros de Atenção Psicossocial, residências terapêuticas etc.) mas que se encontra sob permanente ameaça de setores conservadores da psiquiatria. Essa reforma nos permitiu também avançar na construçáo da Política Nacional de Humanização, que tem como fundamentos as tecnologias relacionais, a clínica ampliada e o cuidado com o cuidador ${ }^{26}$.

Avançamos muito no fortalecimento das instituiçóes de ensino como a Fundação Oswaldo Cruz, as universidades, as escolas técnicas em saúde. Houve muitos avanços na pesquisa em Saúde Coletiva, na formação de especialistas e pós-graduados. Um bom exemplo foi o ocorrido com a Zika congênita, onde uma articulação entre clínica, vigilância epidemiológica e pesquisa, deram condições para que o Brasil pudesse se colocar em uma posição diferenciada em termos científicos e de saúde pública, nessa questão.

O SUS tem cumprido um papel central na qualificaçáo da democracia brasileira através do trabalho dos Conselhos Municipais, estaduais e nacional de saúde; além das conferencias de saúde realizadas a cada quatro anos. É um modo de exercitar a democracia direta que tem sido copiado por outras esferas das políticas públicas.

Uma outra dimensão ainda pouco compreendida, está muito presente neste momento de pandemia, em que a sociedade brasileira ameaçada pelo assustador número de mortes (120 mil mortes no início de setembro) cobra dos governos o acesso a equipamentos, produtos e tecnologias para o adequado enfrentamento da COVID 19. Essa dura percepção de vulnerabilidade do nosso sistema de saúde e da dificuldade de acesso a insumos e tecnologias estratégicas para seu enfrentamento, nos permite apreender a dualidade da saúde. Ela é ao mesmo tempo uma política central para a melhoria das condiçóes de vida, mas também uma área dinâmica com múltiplas dimensôes: assistencial, econômica, científica e tecnológica.

O complexo econômico industrial da saúde (CEIS) incorpora um conceito e uma política desafiadora para um país como o Brasil. Nessa perspectiva o SUS, o maior sistema universal do mundo, está assentado em uma base frágil em relação à nossa capacidade 
produtiva e tecnológica. É preciso estabelecer um novo padrão de política pública que articule diferentes indústrias (farmacêutica e biotecnológica, de equipamentos e materiais médicos) com os serviços de saúde ${ }^{27}$.

A vulnerabilidade existente para garantir o acesso universal e a necessidade de desenvolver um vigoroso sistema produtivo e de inovação em saúde exigiram a busca de soluções. Foi com essa concepção que se iniciou, a partir de 2007, a política de fortalecimento do CEIS para que o Brasil construísse uma base produtiva que fizesse frente às vulnerabilidades no acesso à saúde. No processo de desenvolvimento da política, a utilização do poder de compra do Estado foi utilizada para desenvolver a produção local em parceria com empresas privadas, considerando que a saúde é reconhecidamente uma área de elevadíssimas falhas de mercado, de jogo competitivo monopolista e de práticas abusivas de toda ordem ${ }^{27}$.

A questão central, portanto, é, como reduzir a dependência de tecnologia produzida externamente? Ou seja, como articular as políticas de saúde, de inovação e industrial para construir uma política de Estado visando reduzir essa dependência e fortalecer a capacidade produtiva nacional? Para um entendimento mais claro é preciso compreender a dimensão econômica e tecnológica da saúde.

Em 2016 o PIB do Brasil foi de 6 trilhóes de reais. A conta saúde, ou seja, a soma de tudo do ponto de vista econômico que envolveu saúde - emprego, salário, serviços, produção, indústrias - foi de 600 bilhóes, ou seja, 10\% do PIB. São 12 milhões de trabalhadores com empregos diretos ou indiretos, e significa um quarto do esforço nacional de pesquisa e desenvolvimento em saúde. A saúde é plataforma das tecnologias de fronteira crítica do conhecimento - nanotecnologia, química fina, microeletrônica, telemedicina, biotecnologia, novos materiais ${ }^{27}$.

Infelizmente a partir de 2016 essa política se fragilizou o que teve impacto neste momento no acesso a respiradores, a equipamentos de proteção, a testes e outros produtos. Essa política de Estado, implementada por ministros de diferentes partidos e concepçóes, foi fragilizada ainda mais com a extinção do Grupo Executivo do Complexo Industrial da Saúde (GECIS) em dezembro de 2017. Hoje, ele cumpriria importante papel no enfrentamento da pandemia, pois articulava, sob o comando do Ministério da Saúde, 14 ministérios e instituiçôes públicas, envolvendo da Casa Civil aos ministérios da área econômica e da indústria e de CT\&I (ciência, tecnologia e inovação) ${ }^{28}$.

É impossível imaginar construir o SUS que queremos sem garantir a sua sustentabilidade tecnológica, e para isso temos que reduzir nossa dependência e fortalecer o Complexo Econômico-Industrial da Saúde. 


\section{O QuE NÁO DEU CERTO E ONDE} TIVEMOS MAIS DIFICULDADES

Mas muita coisa não deu certo, muito se perdeu nessa caminhada.

Uma análise possível é que, se de fato houve uma ampliação da cobertura e a inclusão de relevantes problemas de saúde no leque de políticas e programas implementados ao longo dessa década; isso não foi acompanhado da organização de redes efetivamente integradas, humanizadas, de cuidado integral e referenciadas, que de fato tivessem incorporado esse conjunto de conceitos em seu processo cotidiano de trabalho. Embora existam inúmeras experiências em vários municípios nesse sentido, estamos muito aquém do que poderia ter sido feito nesse campo. Não conseguimos também que a Estratégia Saúde da Família fosse de fato a única porta de entrada do sistema e a estratégia de reorientação setorial sobre a qual se sustentasse os demais níveis de complexidade.

Da mesma forma, as desigualdades entre as regióes e acesso entre as classes foram reduzidas, mas ainda se encontram em níveis insustentáveis.

Se o projeto original foi a construção de um sistema único para todos e um direito universal, na prática, ao invés desse sistema, onde a dinâmica do setor privado estivesse regulada por um Estado forte e competente, nós criamos duas estruturas desarticuladas: o sistema SUS de um lado e o arranjo de múltiplos prestadores de planos e seguros no mercado privado, de outro lado. Ao contrário da diretriz aprovada na VIII CNS de progressiva ampliação da participação pública na oferta de serviços de saúde, o que se observou ao longo destas décadas foi uma expressiva expansão da rede privada vinculada ao setor da saúde suplementar. O mercado de seguradoras e planos de saúde se expandiu fortemente expressando um complexo fenômeno econômico, político e cultural.

O SUS é visto como pouco eficiente e um sistema para os mais pobres. E o próprio Estado brasileiro tem essa visão, muito presente no executivo, no Legislativo e no Judiciário. Não conseguimos avançar na questão da intersetorialidade nas grandes áreas: assistência social, educação, saúde, economia, segurança, meio ambiente, saneamento continuam como espaços burocráticos isolados com pouco diálogo e interaçáo. Náo tivemos uma estratégia de comunicação em saúde competente, com a exceção do Canal Saúde da Fiocruz, sendo que a grande mídia continua como um espaço contraditório, influenciada por uma gama de indústrias com interesses lucrativos em relação à Saúde Pública.

Existe um fenômeno muito curioso que é uma transmigração de filantropia e caridade para o SUS. Isso é importante porque os valores que nos orientam há décadas, como igualdade e solidariedade perde espaço. $\mathrm{O}$ ideário do SUS é ser universal, sem diferenciar status ou renda, na oferta de atendimento 
integral e de qualidade e atuar na dimensão coletiva com a saúde como um Direito, portanto ele entra em conflito direto com o paradigma dominante que está sendo vendido hoje, principalmente para a nova geração, que é o consumismo, o empreendedorismo, o individualismo, o mercantilismo. Nessa concepção, quem pode mais, paga por uma saúde melhor.

O espaço da gestão é um dos mais críticos no processo de construção do SUS. Como se constrói um modelo moderno, que garanta o funcionamento de redes integradas com dedicação exclusiva para o serviço público? Aqui existe um conflito e choque de visôes importantes dentro do próprio movimento da Reforma Sanitária. A proposta da criação das Fundaçôes Públicas de direito privado em 2008 foi duramente atacada por setores corporativos e esse conflito levou à atual hegemonia das Organizaçôes Sociais que continuam sendo vistas como um modelo híbrido, recentemente envolvidas a nível nacional em escânda-los de desvio de recursos públicos. Além disso, temos uma gestão muito partidarizada com um excessivo quadro de cargos de confiança de livre nomeação.

\section{CONSIDERAÇÓEES FINAIS}

Nosso SUS é produto de um longo e complexo processo histórico de luta pela construção de cidadania e da saúde como um direito. $\mathrm{O}$ ideário que move os princípios da chamada Reforma Sanitária Brasileira pode ser sintetizada em uma frase do saudoso Sérgio Arouca: "Trata-se de um processo civilizatório". Esse movimento político e ideológico encontra sua maturidade durante o processo constituinte e consegue inscrever na constituição brasileira que a saúde é um direito de todos e dever do estado. Importante lembrar que esse movimento político desde seu início colocava para a sociedade uma visão ampliada de saúde centrada na questáo de que a saúde é socialmente e politicamente determinada. Ou seja, não se tratava (e continua sendo assim) apenas de construir um sistema de atenção à saúde. Nesses mais de 30 anos, a saúde brasileira sofreu profundas transformaçôes para melhor.

O SUS é um sucesso como macro estratégia para impactar os indicadores sanitários. Sem o SUS, hoje, viveríamos um processo de barbárie social. Mas apesar disso, com todos os avanços, a avaliação da população com frequência é negativa em termos de acesso, qualidade, tempo de espera, desumanização e descoordenação. É sobre isso que temos de nos debruçar para discutir o SUS que queremos. Há uma outra dimensão referente ao processo de desenvolvimento do país e da sociedade brasileira. $\mathrm{Na}$ minha opiniáo a existência do SUS é fator fundamental no processo de construçáo de um país efetivamente desenvolvido e obstáculo à implantação no 
nosso país da barbárie disfarçada de modernidade que é a disseminação de uma visão da saúde vista como mercadoria ou bem a ser comprado no mercado de acordo com a capacidade de gasto de famílias ou empresas. E que sem o SUS, um país com tanta desigualdade não conseguirá sequer pensar em um modelo de desenvolvimento que reduza a desigualdade e aumente a equidade. $\mathrm{Ou}$ seja, as nossas raízes históricas centradas no colonialismo, escravatura e patrimonialismo, e uma sociedade baseada em desigualdades, iniquidades, opressôes e privilégios, o SUS, ao longo de três décadas, mostra que é um instrumento poderoso para enfrentar essa estrutura. Para melhorar as condiçóes de vida da população brasileira. E para defender o SUS, temos que defender a democracia. Defender a democracia e lutar por uma saúde universal é desafio fundamental no atual contexto.

Temos dois projetos em conflito. O SUS: universal, integral, equitativo, financiado com recursos do orçamento fiscal para todos, sem distinção, ou o fortalecimento do setor de planos e seguros de saúde do setor privado, sustentado por políticas de subsídio ao mercado e de renúncia fiscal e baseado no discurso de que a questão social não cabe no orçamento da nação, deixando o SUS para os mais pobres. Qual dos dois projetos prevalecerá?

Para a sobrevivência e desenvolvimento do SUS é preciso fortalecer a consciência po- lítica de que o sistema universal é o melhor caminho para a justiça social e a proteção para a saúde de todos, sem distinção.

\section{Agradecimentos}

A todos que constroem cotidianamente o SUS há 32 anos

\section{CONFlito DE INTERESSE}

$\mathrm{O}$ autor declara não haver qualquer conflito de interesse neste estudo.

\section{REFERÊNCIAS BIBLIOGRÁRICAS}

1. OLIVEIRA, Jaime de Araujo; FLEURY TEIXEIRA, Sonia Maria. (Im)previdência Social: 60 anos da história da Previdência no Brasil. Petrópolis: Vozes, 1985.

2. ESCOREL, Sarah. Reviravolta na saúde: origem e articulação do movimento sanitário. Rio de Janeiro: Editora Fiocruz. 1999.

3. AROUCA, Antônio Sérgio da Silva. A reforma sanitária brasileira. Tema/Radis, Rio de Janeiro, n.11, p.2-4. 2002.

4. HAJDU SI. A note from history: Rudolph Virchow, pathologist, armed revolutionist, politician, and 
anthropologist. Ann Clin Lab Sci. 2005;35(2):203-205.

5. BRASIL. Ministério da Saúde. Relatório final da VIII Conferência Nacional de Saúde, 1986.

6. ALMEIDA-FILHO, N. A problemática teórica da determinação social da saúde. In: NOGUEIRA, R. P. (Org.). Determinação Social da Saúde e Reforma Sanitária. Rio de Janeiro: Cebes, 2010. p. 13-36.

7. BRASIL. [Constituição (1988)]. Constituição da República Federativa do Brasil: promulgada em 5 de outubro de 1988. 4. ed. São Paulo: Saraiva, 1990.

8. ORGANIZAÇÃO PARA A COOPERAÇÃO E DESENVOLVIMENTO ECONÓMICO. Financing and Delivering Health Care: A comparative analysis of OECD Countries. Paris: OECD; 1987

9. PAIM, Jairnilson. Reforma Sanitária Brasileira: contribuição para a compreensão crítica. Salvador: Edufba; Rio de Janeiro: Fiocruz, 2008.

10. VIACAVA, Francisco et al. SUS: oferta, acesso e utilização de serviços de saúde nos últimos 30 anos. Ciênc. saúde coletiva [online]. 2018, vol.23, n.6, pp.1751-1762

11. HONE, Thomas (Department of Primary Care and Public Health Imperial College London), Como o Sistema Único de Saúde brasileiro pode apren- der com o Serviço Nacional de Saúde (NHS) do Reino Unido? Apresentado no Seminário "O Futuro dos Sistemas Universais de Saúde" organizado pelo CONASS, abril de 2018, Brasília

12. OCKE-REIS, Carlos Octávio. Financial sustainability of the Brazilian Health System and health-related tax expenditures. Ciênc. saúde coletiva [online]. 2018, vol.23, n.6, pp.2035-2042. ISSN 1678-4561. https://doi.org/10.1590/141381232018236.05992018.

13. IBGE (2019) Conta-Satélite de Saúde: em 2017, 9,2\% do PIB foram gastos no consumo de bens e serviços de saúde, disponível em https://agenciadenoticias. ibge.gov.br/agencia-sala-deimprensa/2013-agencia-de-noticias/ releases/26434-conta-satelite-de-saudeem-2017-9-2-do-pib-foram-gastos-noconsumo-de-bens-e-servicos-de-saude, acessado em 20 de agosto de 2020

14. COMISSÃO NACIONAL SOBRE DETERMINANTES SOCIAIS DA SAÚDE. As causas sociais das iniquidades em saúde no brasil. Rio de janeiro: Fiocruz; 2008

15. BERLINGUER G. Medicina e política. São Paulo: CEBES/Hucitec; 1978

16. TEMPORÃO, José Gomes. A Propaganda de Medicamentos e o Mito da Saúde. Rio de Janeiro: Graal- Paz e Terra, 1986. 
17. Marx, K. O Capital: crítica da economia política. São Paulo: Nova Cultural; 1996

18. TEMPORÁO, J. G., 2002. O Complexo Industrial da Saúde: Público e Privado na Produçáo e Consumo de Vacinas no Brasil. Tese de Doutorado, Rio de Janeiro: Instituto de Medicina Social, Universidade do Estado do Rio de Janeiro.

19. BRASIL, Presidência da República. Decreto no 6.108 de 4 de maio de 2007. Disponível em: http://www.aids. gov.br/pt-br/legislacao/decreto-6108de-4-de-maio-de-2007. Acessado em 02 de setembro de 2020 .

20. LEAL, Maria do Carmo et al. Saúde reprodutiva, materna, neonatal e infantil nos 30 anos do Sistema Único de Saúde (SUS). Ciênc. saúde coletiva [online]. 2018, vol.23, n.6, pp.1915-1928

21. BRASIL. Política Nacional de Atenção Integral à Saúde da Criança: Orientaçôes para implementação. Brasília: Ministério da Saúde, 2018.

22. PINTO, Luiz Felipe and GIOVANELLA, Ligia. Do Programa à Estratégia Saúde da Família: expansão do acesso e reduçáo das internaçóes por condiçôes sensíveis à atenção básica (ICSAB). Ciênc. saúde coletiva [online]. 2018, vol.23, n.6, pp.1903-1914.

23. MINISTÉRIO DA SAÚDE, 2019. Brasil registra aumento no número de transplantes mais difíceis de serem realizados. Disponível em: https:// www.saude.gov.br/noticias/agenciasaude/45850-brasil-registra-aumentono-numero-de-transplantes-maisdificeis-de-serem-realizados. Acesso em 25 de agosto 2020

24. BRASIL. Ministério da Saúde. Política Nacional de Atenção Integral à Saúde do Homem. Plano de Ação Nacional (2009-2011). Brasília, 2009.

25. PORTES, Leonardo Henriques et al. A Política de Controle do Tabaco no Brasil: um balanço de 30 anos. Ciênc. saúde coletiva [online]. 2018, vol.23, n.6, pp. 1837-1848

26. BRASIL. Ministério da Saúde. Secretaria de Atenção à Saúde. Núcleo Técnico da Política Nacional de Humanização. Humaniza/SUS: documento base para gestores e trabalhadores do SUS. 4.ed. Brasília: Ministério da Saúde, 2008.

27. GADELHA, Carlos Augusto Grabois and TEMPORAO, José Gomes. Desenvolvimento, Inovação e Saúde: a perspectiva teórica e política do Complexo Econômico-Industrial da Saúde. Ciênc. saúde coletiva [online]. 2018, vol.23, n.6, pp.1891-1902.

28. TEMPORÃO, JG; GADELHA, CAGTecnologia em saúde: Brasil não pode ficar de joelhos, Folha de São Paulo, 19 de abril de 2020. 